\title{
Hypoglycaemia is associated with increased risk of fractures in patients with type 2 diabetes mellitus: a cohort study
}

\author{
Antiopi Ntouva ${ }^{1, *}$, Konstantinos A Toulis ${ }^{1,2, *}$, Deepikshana Keerthy', Nicola J Adderley ${ }^{1}$, Wasim Hanif ${ }^{3}$, \\ Rasiah Thayakaran', Krishna Gokhale ${ }^{1}$, G Neil Thomas' ${ }^{1}$, Kamlesh Khunti ${ }^{4}$, Abd A Tahrani ${ }^{5,6,7, \dagger}$ and \\ Krishnarajah Nirantharakumar 1,3,6,t
}

${ }^{1}$ Institute of Applied Health Research, University of Birmingham, Birmingham, UK, ${ }^{2} 424$ General Military Hospital, Thessaloniki, Greece, ${ }^{3}$ Diabetes Department, University Hospitals Birmingham NHS Foundation Trust, Birmingham, UK, ${ }^{4}$ Diabetes Research Centre, University of Leicester, Leicester, UK, ${ }^{5}$ Institute of Metabolism and Systems Research, University of Birmingham, ${ }^{6}$ Centre for Endocrinology, Diabetes and Metabolism, Birmingham Health Partners, and ${ }^{7}$ Department of Diabetes and Endocrinology, Birmingham Heartlands Hospital, Birmingham, UK

*(A Ntouva and K A Toulis contributed equally to this work)

†(A A Tahrani and K Nirantharakumar are joint senior authors)

Correspondence should be addressed to $\mathrm{K}$ A Toulis or $\mathrm{K}$ Nirantharakumar Email

K.Toulis@bham.ac.uk or k.nirantharan@bham.ac.uk

\begin{abstract}
Objective: Type 2 diabetes is associated with an increased risk of fracture. Any factor that incrementally increases this risk should be taken into account when individualising treatment. Hypoglycaemia is a common complication of antidiabetes medications and suggested as a risk factor for fractures; yet, its real-life clinical impact is unclear. Design: A population-based, retrospective open cohort study using routinely collected data between 1st of January 1995 and 1st of May 2016 in The Health Improvement Network (THIN) database.

Methods: Patients with type 2 diabetes mellitus with documented hypoglycaemic events were compared to randomly matched patients with type 2 diabetes mellitus without documented hypoglycaemic events matched to exposed patients on age, sex, duration of diabetes and BMI. The primary outcome was any incident fracture. Secondary outcome was incident fragility (osteoporotic) fracture.
\end{abstract}

Results: A total of 41163 patients with type 2 diabetes were included: 14147 patients in the exposed cohort and 27016 patients in the unexposed cohort. Patients with a documented hypoglycaemic event were significantly more likely to sustain any fracture compared to patients with no record of hypoglycaemic events: adjusted IRR $=1.20(95 \%$ $\mathrm{Cl}$ : 1.12-1.30; $P<0.0001)$. Patients who had a documented hypoglycaemic event were significantly more likely to suffer a fragility fracture compared to controls: adjusted IRR $=1.24(95 \% \mathrm{Cl}: 1.13-1.37 ; P<0.0001)$.

Conclusions: Hypoglycaemic events are a significant risk factor for fractures in patients with diabetes mellitus. This observation is clinically relevant when individualising targets for glycaemic control and selecting antidiabetic agents.

\section{Introduction}

Each year in the United Kingdom, 1.8 million fractures occur with an annual incidence of about $3.6 \%$ and a lifetime prevalence of approximately $40 \%(1,2,3)$. The annual cost
European Journal of Endocrinology

(2019) 180, 51-58
(C) 2019 European Society of Endocrinology Printed in Great Britain in the United Kingdom for hip fractures alone including medical and social care is about $£ 2$ billion (4).

Despite their apparently normal areal bone density, patients with type 2 diabetes mellitus have an increased risk of fragility (osteoporotic) fractures $(5,6,7,8,9)$. 
This paradox has been partly attributed to impaired bone microarchitecture and accumulation of advanced glycation end products (6). However, patients with type 2 diabetes mellitus may also be at an increased risk of falls, as a result of concomitant medications (such as antihypertensive treatment), peripheral neuropathy due to diabetes and associated impaired mechano-sensation, orthostatic hypotension caused by autonomic neuropathy and possibly hypoglycaemic events associated with antihyperglycaemic therapy. Considering that there are 4 million people living with type 2 diabetes mellitus in the United Kingdom, and by 2025 , it is estimated that the number will rise to 5 million $(10,11)$, it is important to further our understanding regarding the underlying risk factors that increase the risk of fractures in type 2 diabetes mellitus patients.

Hypoglycaemia is one of the main complications of diabetes treatment and is associated with serious adverse events (12). The majority of studies exploring the association between hypoglycaemic events and fracture risk have used commercial health claims databases (13, $14,15)$ or national hospital and psychiatric registers (16). The latter patients constitute a distinct subset and these findings may not be applicable to the general diabetic population. Thus, there is paucity of evidence regarding the association of hypoglycaemia and fracture in a general population.

Hence, we aimed to assess the association between hypoglycaemia and risk of fracture in patients with type 2 diabetes mellitus using UK primary care data.

\section{Subjects and methods}

\section{Study design}

A population-based, retrospective open cohort study in which patients with type 2 diabetes mellitus with documentation of any hypoglycaemic event were compared to randomly matched patients with type 2 diabetes mellitus without documented hypoglycaemic events. Age, gender, BMI and duration of diabetes mellitus were used as the matching parameters.

\section{Data source}

Data for this study was obtained from The Health Improvement Network (THIN) database, a UK general practice electronic database. Data are entered by general practitioners during each consultation using Read Codes, a hierarchical coding system for structured storage of information (17). More than 675 practices across the UK contribute data to THIN (18). THIN data are generalisable to the UK for major health conditions (19) and have been used for studies exploring hypoglycaemic events in patients with diabetes (20).

\section{Ethics and patient involvement}

This study used routinely collected, anonymised primary care data. Patients were not involved in the study, and therefore, no consent was required. Research using THIN data was approved by the NHS South-East Multicentre Research Ethics Committee in 2003, with the condition that studies undergo independent scientific review. Approval for this analysis was obtained from the Scientific Review Committee for the use of THIN data (SRC reference 16THIN084).

\section{Study population}

Adult patients aged $\geq 18$ with type 2 diabetes mellitus registered in general practices contributing to THIN during the study period (1st of January 1995 to 1st of May 2016) were eligible.

\section{Observation period}

A patient was eligible 1 year after the latest of the following dates: (1) registration in the practice (registration date); (2) introduction of Electronic Medical Record (EMR date) and (3) Acceptable Mortality Recording (AMR) date. AMR is an indicator of when practices started to record information consistently and in a timely manner (21). A 1-year latent period is applied to ensure there was sufficient time to record all important covariates. Follow-up end date (exit date) was the earliest of transfer date (when patient left the practice), death date, first documentation of outcome i.e. fracture (outcome date) or study end date.

\section{Exposed cohort}

Individuals were included in the exposed cohort if they were 18 years or older, had a diagnosis of type 2 diabetes mellitus and a documented hypoglycaemic event. Patients with a history of any fracture were excluded. The exposed cohort was followed up from the date at which they had a documented hypoglycaemic event, which was defined as the index date for the exposed patient. 


\section{Unexposed cohort}

Adult patients with type 2 diabetes mellitus who did not have a documented hypoglycaemic event were eligible for inclusion in the unexposed (control) group. For each exposed patient up to two unexposed controls were randomly selected from patients registered in the same participating general practice. Controls were individually matched to cases on age at index date (within one year), sex, documented duration of diabetes (to within 3 years) and BMI $\left( \pm 2 \mathrm{~kg} / \mathrm{m}^{2}\right)$. The index date of the unexposed patients was the same as the index date of the corresponding exposed patients they were matched on to ensure immortality time bias did not influence our analysis. Patients with a documented history of previous fractures were excluded.

\section{Outcomes and covariates}

Primary outcome was any fracture (fracture at any site during the observation period). Secondary outcome was fragility fracture (fractures at hip, wrist, spine and humerus were considered as such). Diagnosis of diabetes mellitus, fractures and hypoglycaemic events were determined by Read codes using previously published methodologies and definitions noted in literature $(22,23,24)$.

Potential confounders were used as model covariates (in addition to matching parameters) and were selected on the basis of biological plausibility. These covariates were Townsend deprivation index (a measure of social deprivation), smoking status, Charlson Comorbidity Index (which includes diabetic complications such as peripheral neuropathy and retinopathy), HbA1c, insulin use (25), bisphosphonate use, systemic steroids, hyperthyroidism or Graves' disease, renal impairment, alcohol intake, glitazones use, antihypertensive medications and stroke and TIA.

\section{Statistical analysis}

The study cohort was described using appropriate descriptive statistics. Incidence of the outcome of interest was compared between the exposed and unexposed group. IRR were derived using Poisson regression adjusting for covariates. The covariates were age, sex, BMI, Townsend Deprivation Index, smoking, Charlson Comorbidity Index, HbA1c, insulin use, bisphosphonate use, systemic steroids prescriptions, hyperthyroidism or Graves' disease, renal impairment and antihypertensive medications. Statistical significance was determined at $P<0.05$.
A sensitivity analysis including only incident diabetes patients (patients who developed diabetes after becoming eligible to participate in the study) was conducted. This was to explore impact of any biases of under-recording of hypoglycaemic consultation in patients who had diabetes either before the practice became eligible to participate or before they registered with the practice. In an analysis limited to the exposed incident hypoglycaemic patients we explored if an increasing number of documentation of hypoglycaemia per year was associated with increased risk of fractures. For this analysis, four groups were determined based on quartiles of the exposure of interest. Exposure of interest was defined as number of hypoglycaemic presentation per year of follow-up. The groups were hypoglycaemic recording once in more than 4.0 years (low incidence: quartile 1 ), once in $2.0-4.0$ years (quartile 2 ), once in 0.85-2.0 years (quartile 3 ) and once in less than 0.85 years (high incidence: quartile 4 ).

\section{Results}

A total of 41163 patients with type 2 diabetes were included in the study population; 14147 patients were included in the exposed cohort (patients with a documented hypoglycaemic event at their index date) and 27016 patients were included in the unexposed cohort (Table 1). A flow chart summarising the formation of the study population is presented in the Supplementary Fig. 2 (see section on supplementary data given at the end of this article). Across the whole study population at baseline, $52.3 \%$ were male; median (interquartile range) age was 69.4 (58.2-77.7) years; mean (standard deviation (s.D.)) BMI was $29.5(6.1) \mathrm{kg} / \mathrm{m}^{2}$; mean (s.D.) HbA1c was $59.9(17.8) \mathrm{mmol} / \mathrm{mol}$ and mean (s.D.) duration of diabetes was 10.9 (8.3) years. Patients in the exposed group had poorer glycaemic control, had more comorbidities, were more likely to be on systemic steroids and were twice as likely to be taking insulin compared to patients in the unexposed group. For all fractures, median (IQR) and mean (s.D.) follow-up were 3.3 (1.4-6.3) and 4.3 (3.5) years respectively; for fragility fractures, median and mean follow-up were 3.3 (1.4-6.3) and 4.3 (3.5) years respectively. During the observation period, a total of 3215 fractures (1238 in patients with documented hypoglycaemic events) were recorded, out of which 1957 (758 in patients with documented hypoglycaemic events) were considered to be fragility fractures.

Patients with type 2 diabetes who had a documented hypoglycaemic event were significantly more likely to 
Table 1 Baseline characteristics of diabetes patients with and without documented hyoglycaemia.

\begin{tabular}{|c|c|c|}
\hline & Hypoglycaemia & No hypoglycaemia \\
\hline$n(\%)$ & $14147(34.4 \%)$ & $27016(65.6 \%)$ \\
\hline \multicolumn{3}{|l|}{ Gender } \\
\hline Male & $7355(52.0 \%)$ & $14166(52.4 \%)$ \\
\hline Female & $6792(48.0 \%)$ & $12850(47.6 \%)$ \\
\hline \multicolumn{3}{|l|}{ Age } \\
\hline Mean (S.D.) & $66.8(15.0)$ & $67.1(14.5)$ \\
\hline Median (IQR) & $69.3(57.9-77.8)$ & $69.4(58.4-77.7)$ \\
\hline \multicolumn{3}{|l|}{ BMI categories } \\
\hline$<25 \mathrm{~kg} / \mathrm{m}^{2}$ & $3337(23.6 \%)$ & $5873(21.7 \%)$ \\
\hline $25-30 \mathrm{~kg} / \mathrm{m}^{2}$ & $4895(34.6 \%)$ & $9833(36.4 \%)$ \\
\hline$>30 \mathrm{~kg} / \mathrm{m}^{2}$ & $5488(38.8 \%)$ & $10452(38.7 \%)$ \\
\hline Missing or implausible values & $427(3.0 \%)$ & $858(3.2 \%)$ \\
\hline \multicolumn{3}{|l|}{ Townsend score* } \\
\hline 1 & $2678(18.9 \%)$ & $5568(20.6 \%)$ \\
\hline 2 & $2728(19.3 \%)$ & $5475(20.3 \%)$ \\
\hline 3 & $2996(21.2 \%)$ & $5588(20.7 \%)$ \\
\hline 4 & $2873(20.3 \%)$ & $5474(20.3 \%)$ \\
\hline 5 & $2273(16.1 \%)$ & $3841(14.2 \%)$ \\
\hline Missing or implausible values & $599(4.2 \%)$ & $1070(4.0 \%)$ \\
\hline \multicolumn{3}{|l|}{ HbA1c categories } \\
\hline$\leq 47.5 \mathrm{mmol} / \mathrm{mol}$ & $2479(17.5 \%)$ & $5674(21.0 \%)$ \\
\hline $47.5-58.5 \mathrm{mmol} / \mathrm{mol}$ & $3785(26.8 \%)$ & $7930(29.4 \%)$ \\
\hline $58.5-69.4 \mathrm{mmol} / \mathrm{mol}$ & $2438(17.2 \%)$ & $4270(15.8 \%)$ \\
\hline$\geq 69.4 \mathrm{mmol} / \mathrm{mol}$ & $3202(22.6 \%)$ & $4874(18.0 \%)$ \\
\hline Missing or implausible values & $2243(15.9 \%)$ & $4268(15.8 \%)$ \\
\hline \multicolumn{3}{|l|}{ Smoker } \\
\hline Yes & $2015(14.2 \%)$ & $3755(13.9 \%)$ \\
\hline \multicolumn{3}{|l|}{ Alcohol } \\
\hline Non-drinker & $4689(33.1 \%)$ & $8195(30.3 \%)$ \\
\hline Drinker & $7952(56.2 \%)$ & $16619(61.5 \%)$ \\
\hline Excessive drinker & $590(4.2 \%)$ & $770(2.9 \%)$ \\
\hline Missing or implausible values & $916(6.5 \%)$ & $1432(5.3 \%)$ \\
\hline \multicolumn{3}{|l|}{ eGFR categories } \\
\hline$>90$ (stage 1 ) & $2752(19.5 \%)$ & $5593(20.7 \%)$ \\
\hline $60-90$ (stage 2) & $6053(42.8 \%)$ & $12853(47.6 \%)$ \\
\hline 30-59 (stage 3) & $3992(28.2 \%)$ & $6704(24.8 \%)$ \\
\hline$<30$ (stage 4$)$ & $796(5.6 \%)$ & $761(2.8 \%)$ \\
\hline Missing or implausible values & $554(3.9 \%)$ & $1105(4.1 \%)$ \\
\hline \multicolumn{3}{|c|}{ Charlson comorbidity index categories } \\
\hline 1 & $5715(40.4 \%)$ & $12809(47.4 \%)$ \\
\hline 2 & $3502(24.8 \%)$ & $6589(24.4 \%)$ \\
\hline 3 & $2275(16.1 \%)$ & $4040(15.0 \%)$ \\
\hline$\geq 4$ & $2655(18.8 \%)$ & $3578(13.2 \%)$ \\
\hline \multicolumn{3}{|l|}{ Baseline medical conditions } \\
\hline Graves or hyperthyroidism & $306(2.2 \%)$ & $513(1.9 \%)$ \\
\hline Cardiovascular disease & $5158(36.5 \%)$ & $8835(32.7 \%)$ \\
\hline Documented osteoporosis & $335(2.4 \%)$ & $564(2.1 \%)$ \\
\hline \multicolumn{3}{|l|}{ Drugs } \\
\hline Insulin & $6188(43.7)$ & $5646(20.9)$ \\
\hline Metformin & $6906(48.8)$ & $13534(50.1)$ \\
\hline Sulfonylureas & $5852(41.4)$ & $8114(30.0)$ \\
\hline Acarbose & $101(0.7)$ & $193(0.7)$ \\
\hline DPP4i & $695(4.9)$ & $1082(4.0)$ \\
\hline Glinides & $77(0.5)$ & $117(0.4)$ \\
\hline Glitazones & $1154(8.2)$ & $2165(8.0)$ \\
\hline GLP1-RA & $145(1.0)$ & $347(1.3)$ \\
\hline SGLT2i & $31(0.2)$ & $54(0.2)$ \\
\hline Systemic steroids & $752(5.3)$ & $806(3.0)$ \\
\hline Biphosphonates & $387(2.7)$ & $623(2.3)$ \\
\hline Anti-hypertensives & $10.603(74.9)$ & $19833(73.4)$ \\
\hline
\end{tabular}

Townsend deprivation score is a composite score with a maximum total score of 94 to measure 13 categorises of deprivation (Townsendj 1987). This score is categorised into quintiles ranging from least deprived to most deprived and widely used in THIN studies.

BMI, body mass index; DPP-4i, dipeptidyl peptidase-4 inhibitors; eGFR, estimated glomerular filtration rate; GLP1-RA, glucagon-like peptide-1 receptors agonists; HbA1c, glycated haemoglobin A1c; SGLT2i, sodium-glucose co-transporter-2 inhibitors. suffer any fracture compared to patients with type 2 diabetes in the unexposed matched cohort: crude IRR 1.29 (95\% CI 1.20-1.38; $P<0.0001)$. Adjusting for preselected covariates (age, sex, BMI, Townsend score, smoking status, alcohol consumption, HbA1c, Charlson Comorbidity Index, presence of Graves' disease or hyperthyroidism, and use of insulin, systemic steroids, bisphosphonates or glitazones), the findings remained significant (adjusted IRR 1.20 (95\% CI 1.12-1.30; $P<0.0001$ ) (Fig. 1 and Table 2)). Findings remained significant in the sex-specific analysis (men 1.16 (95\% CI 1.02-1.32; $P=0.023)$; women 1.23 (95\% CI 1.12-1.34; $P<0.001)$ ). Similarly, the effect sizes did not change in women when age was also taken into consideration (women with age $\leq 65$ years: $1.20(95 \%$ CI: $1.02-1.41 ; P=0.032)$ and age $>65$ years: $1.25(95 \% \mathrm{CI}$ : $1.12-1.40 ; P<0.001)$. In men, the risk was more evident in those aged above 65 years (age $\leq 65$ years 1.11 (95\% CI: $0.89-1.37 ; P=0.35)$ and age $>65$ years $1.20(95 \% \mathrm{CI}$ : $1.02-1.41 ; P=0.027)$ ).

Patients with type 2 diabetes and a documented hypoglycaemic event were significantly more likely to sustain fragility fracture compared to patients with diabetes in the unexposed cohort (crude IRR 1.29 (95\% CI: 1.18-1.42; $P<0.0001)$ and aIRR 1.24 (95\% CI: 1.13-1.37; $P<0.0001$ ) (Fig. 1 and Table 2)). Findings were significant in women but did not reach statistical significance in men in the sex-specific analysis (men 1.19 (95\% CI: 1.00-1.42; $P=0.053$ ); women 1.27 (95\% CI: 1.13-1.42; $P<0.001)$ ). Effect sizes were similar for both sexes below and above 65 years (women: age $\leq 65$ years 1.26 (95\% CI: 1.00-1.58; $P=0.053)$ and age $>65$ years 1.28 (95\% CI: $1.12-1.46$; $P<0.001)$; and men: age $\leq 65$ years 1.16 (95\% CI: $0.82-$ $1.64 ; P=0.400)$ and age $>65$ years 1.20 (95\% CI: $0.98-1.47$; $P=0.078)$ ).

Sensitivity analysis, in which only patients with incident type 2 diabetes were included (Table 3 ), confirmed the difference in rates of fragility fracture between those with and without a documented hypoglycaemic event (crude IRR=1.45 (95\% CI: 1.20-1.76; $P<0.0001$ ); aIRR $=1.33(95 \%$ CI: 1.08-1.67; $P=0.007))$. Similarly, when all fractures were considered, crude IRR was found to be increased to 1.39 (95\% CI: $1.20-1.61 ; P<0.0001)$, and adjusted IRR to 1.26 (95\% CI: $1.08-1.47 ; P=0.004)$ (Table 3).

To explore a potential exposure-outcome relationship, a further analysis limiting to incident exposed patients alone was performed. This analysis suggested a gradient increase in fragility fracture with an IRR of 2.16 (95\% CI 1.35-3.46) in quartile 2, IRR of 3.62 (95\% CI: $2.27-5.79)$ in quartile 3 and IRR of 9.35 (95\% CI: 5.79-15.10) in quartile 
4 in comparison to quartile 1 . A similar trend was also noted for any fractures, IRR of 2.16 (95\% CI: 1.51-3.09) in quartile 2, IRR of 3.86 (95\% CI: 2.71-5.49) in quartile 3 and IRR of 10.23 (95\% CI: 7.11-14.74) in quartile 4.

\section{Discussion}

In this population-based study using a large UK primary care database, hypoglycaemia was associated with a statistically significant (and robust to sensitivity analyses) $20 \%$ increase in the risk of fractures.

A recent meta-analysis of observational studies reported increased odds of fracture in patients with documented hypoglycaemic events (12). However, there are important differences between our study and the studies included in the meta-analysis. Importantly, in the study by Johnston et al. (14), the estimate of which was the most influential on the meta-analysis (assigned the more weight), hypoglycaemic events were allowed to occur at any time during evaluation period, including after fracture; while in our study, the direction of the relationship is clear as the hypoglycaemic events occurred before the occurrence of the fractures. Moreover, in the study by Rajpathak et al. (13), only sulfonylurea users and hip fractures were considered, while our study included
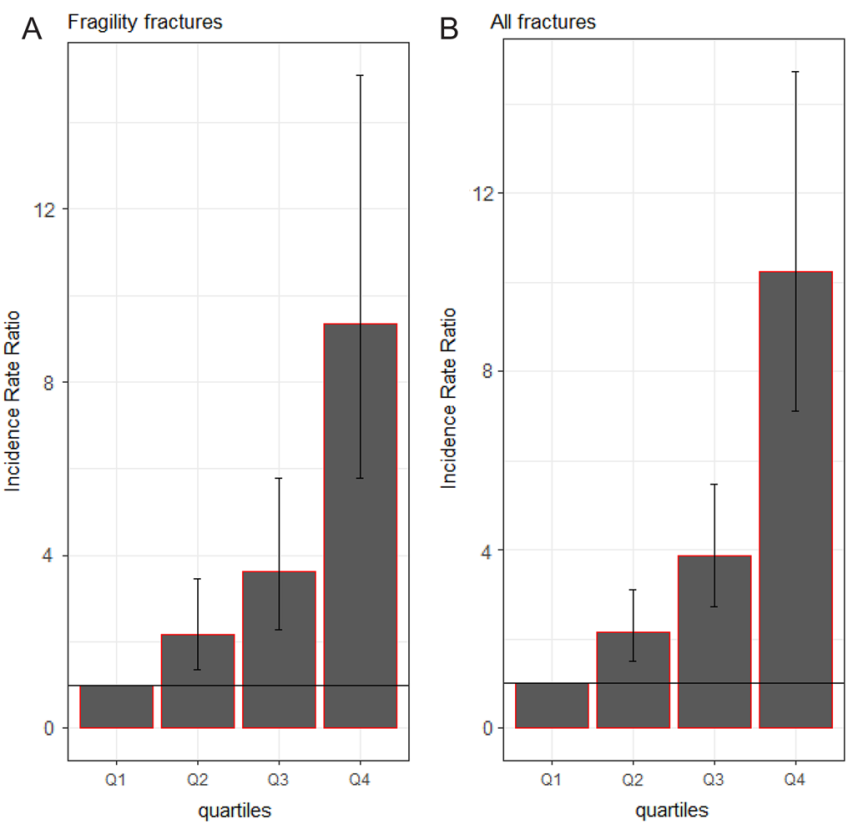

\section{Figure 1}

Cumulative incidence for all fractures and fragility fractures in patients presenting with hypoglycaemia compared to patients with no record of hypoglycemia. all fractures and a wider population of patients with type 2 diabetes mellitus receiving any treatments including insulin, which has been shown to be associated with increased fracture risk (26). A meta-analysis reported that patients with T2DM had a greater risk of low-energy fracture, especially of the hip, yet identified the presence of publication bias (27). Collectively, these observations may indicate a need for caution in the interpretation of the findings of this meta-analysis and justify the need for this study. Finally, our estimate is rather moderate in comparison with the $70 \%$ increase in the risk of hip fracture reported in a recent study perfomed in patients from Taiwan with severe hypoglycaemia (28). However, the differences in ethnic background, intensity of hypoglycaemic events and site of fractures explored may account for the difference in the magnitude of effect.

In the ACCORD trial, intensive glycaemic control was associated with increased frequency of hypoglycaemia compared to standard glycaemic therapy (16.2 vs $5.1 \%$ ) (29). However, intensive glycaemic control did not increase the risk of non-spinal fractures or falls in the ACCORD trial compared to the control arm (29). Several differences between the studies could explain the discrepancies between the results of our study and that of ACCORD. The ACCORD trial population was highly selective and excluded patients at high risk of hypoglycaemia, while our study was population based. In addition, this secondary analysis for the ACCORD trial only included non-spinal fractures while our study included all fractures. The follow-up duration was also much longer in our study compared to ACCORD. Finally, the ACCORD BONE was not adequately powered to detect a $20 \%$ increase in the relative rate of fractures (similar to what reported in our study) as the authors stated in their publication (29).

There are several plausible explanations for the observed increase in the risk of fractures in patients with hypoglycaemia. Apparently, hypoglycaemia might increase the risk of falls, yet the data in ACCORD BONE did not show an increase risk of falls in patients in the intensive glycaemic control arm, although this could be attributable to recall bias (29). As an alternative explanation, hypoglycaemia can also occur in the context of autonomic neuropathy resulting in reduced hypoglycaemia awareness and autonomic neuropathy could result in postural hypotension and increased risk of falls. In addition, hypoglycaemia has also been proposed as a sign of frailty, while simpler explanations (such as hypoglycaemic events leading to road traffic accidents resulting in fractures) should also be taken into account. However, this study was not designed 
Table 2 Risk of fragility fracture and any fracture in patients with type 2 diabetes with documented hypoglycaemia compared to those without.

\begin{tabular}{|c|c|c|c|c|c|c|c|c|}
\hline Outcome & Exposure & $\boldsymbol{n}(\%)$ & Person years & $\begin{array}{c}\text { Incidence } \\
\text { rate (per } 1000 \\
\text { person years) }\end{array}$ & $\begin{array}{c}\text { Incidence rate } \\
\text { ratio }(95 \% \mathrm{Cl})\end{array}$ & $\boldsymbol{P}$ & $\begin{array}{c}\text { Adjusted } \\
\text { incidence rate } \\
\text { ratio }(95 \% \mathrm{Cl})\end{array}$ & $\boldsymbol{P}$ \\
\hline All & Hypoglycaemia & $1238(8.8)$ & 55931.6 & 22.1 & $1.29(1.20-1.38)$ & $<0.0001$ & $1.20(1.12-1.30)$ & $<0.0001$ \\
\hline fractures & No hypoglycaemia & $1977(7.3)$ & 115001.5 & 17.2 & 1 & & 1 & \\
\hline Fragility & Hypoglycaemia & $758(5.4)$ & 57607.3 & 13.2 & $1.29(1.18-1.42)$ & $<0.0001$ & $1.24(1.13-1.37)$ & $<0.0001$ \\
\hline fractures & No hypoglycaemia & $1199(4.4)$ & 117860.7 & 10.2 & 1 & & 1 & \\
\hline
\end{tabular}

to explore the underlying mechanism explaining the association of hypoglycaemia and fractures; this is an area for future study.

The findings of the present study should be interpreted in the context of its limitations. It should be acknowledged that this is retrospective evidence and caution for associated bias should be applied. Although the study was designed to minimise its effect by using a representative sample of the UK population, following a fracture site and medication-agnostic approach, ascertaining the temporal sequence of exposure and outcome, and matching on key determinants of fracture risk (namely age, sex and BMI) as well as diabetes duration, residual bias including outcome definition may still be present. Reassuringly, our estimates were robust to the adjustment for covariates including medications (insulin, corticosteroids, bisphosphonates and glitazones), basic demographics, lifestyle and renal function. To further eliminate the risk of bias, we performed a sensitivity analysis limiting to incident cases with diabetes mellitus, which also confirmed the robustness of our findings. Finally, a higher prevalence of diabetes complications in the insulin-treated patients may be an additional contributing factor to the apparent increase of the incidence of fractures in this subset of patients. However, the selection of diabetes duration as a matching parameter ensures a similar period for any development of any diabetes-related complication between patients and controls and, thus, may offset (at least in part) any potential imbalance. Of note, it was no feasible to assess the severity of hypoglyceamic events (levels of hypoglycaemia) due to the nature of data. Finally, misclassification bias, differences in the definition and documentation of hypoglycaemia across practices, unmeasured confounding, missing data and changing eligibility over time should also be taken into consideration when interpreting the results of realworld data.

The clinical ramifications of the study may be relevant in the management of diabetes mellitus. Treatments that do not increase the risk of hypoglycaemia would be preferable particularly in patients with high risk of fractures. In addition, when considering the individualised $\mathrm{HbA1c}$ treatment target the association between hypoglycaemia and fractures could be taken into account and a higher HbA1c target may be advisable in a patient with increased risk of fracture. Using the same line of reasoning, a 'drug holiday' could be deterred in the management of osteoporosis in a patient with diabetes mellitus, in whom diabetes complications are present or frequent hypoglycaemic events are present or expected.

In conclusion, the risk of any fracture and fragility fracture were found to be significantly higher in patients with type 2 diabetes mellitus and incident hypoglycaemia compared to those without hypoglycaemia. Treatment strategies to reduce the risk of hypoglycaemia might contribute to lowering this increased risk of fracture. These findings may be clinically relevant when individualising targets for glycaemic control and optimising the selection of antidiabetic medications.

Table 3 Risk of fragility fracture and any fracture in patients with incident type 2 diabetes and documented hypoglycaemia compared to those without.

\begin{tabular}{|c|c|c|c|c|c|c|c|c|}
\hline Outcome & Exposure & $\boldsymbol{n}(\%)$ & $\begin{array}{l}\text { Person } \\
\text { years }\end{array}$ & $\begin{array}{c}\text { Incidence rate } \\
\text { (per } 1000 \\
\text { person years) }\end{array}$ & $\begin{array}{l}\text { Incidence rate } \\
\text { ratio }(95 \% \mathrm{Cl})\end{array}$ & $\boldsymbol{P}$ & $\begin{array}{c}\text { Adjusted } \\
\text { incidence rate } \\
\text { ratio }(95 \% \mathrm{Cl})\end{array}$ & $\boldsymbol{P}$ \\
\hline \multirow{2}{*}{$\begin{array}{l}\text { All } \\
\text { fractures }\end{array}$} & Hypoglycaemia & $282(6.9)$ & 15383.2 & 18.3 & $1.39(1.20-1.61)$ & $<0.0001$ & $1.26(1.08-1.47)$ & 0.004 \\
\hline & No hypoglycaemia & $488(5.4)$ & 37057.9 & 13.2 & & & & \\
\hline \multirow{2}{*}{$\begin{array}{l}\text { Fragility } \\
\text { fractures }\end{array}$} & Hypoglycaemia & $165(4.1)$ & 15765.2 & 10.5 & $1.45(1.20-1.76)$ & $<0.0001$ & $1.33(1.08-1.63)$ & 0.007 \\
\hline & No hypoglycaemia & $272(3.0)$ & 37737.9 & 7.2 & & & & \\
\hline
\end{tabular}




\section{Supplementary data}

This is linked to the online version of the paper at https://doi.org/10.1530/ EJE-18-0458.

\section{Declaration of interest}

The authors declare that there is no conflict of interest that could be perceived as prejudicing the impartiality of this study.

\section{Funding}

This research did not receive any specific grant from any funding agency in the public, commercial or not-for-profit sector.

\section{Acknowledgements}

$\mathrm{K} \mathrm{N}$ is the guarantor of the study and has full access to the data. N A is funded by the National Institute for Heath Research (NIHR) Collaboration for Leadership in Applied Health Research and Care (CLAHRC) West Midlands initiative and Prof. K K is funded by NIHR CLAHRC East Midlands. This paper presents independent research and the views expressed are those of the author(s) and not necessarily those of the NHS, the NIHR or the Department of Health. Abd A Tahrani and Krishnarajah Nirantharakumar: Joint senior authors.

\section{References}

1 Baker R, Orton E, Tata LJ \& Kendrick D. Epidemiology of poisonings, fractures and burns among 0-24 year olds in England using linked health and mortality data. European Journal of Public Health 201626 940-946. (https://doi.org/10.1093/eurpub/ckw064)

2 Donaldson LJ, Reckless IP, Scholes S, Mindell JS \& Shelton NJ. The epidemiology of fractures in England. Journal of Epidemiology and Community Health 200862 174-180. (https://doi.org/10.1136/ jech.2006.056622)

3 Bridgman S \& Wilson R. Epidemiology of femoral fractures in children in the West Midlands region of England 1991 to 2001. Journal of Bone and Joint Surgery British 200486 1152-1157.

4 Williamson S, Landeiro F, McConnell T, Fulford-Smith L, Javaid MK, Judge A \& Leal J. Costs of fragility hip fractures globally: a systematic review and meta-regression analysis. Osteoporosis International 2017 28 2791-2800. (https://doi.org/10.1007/s00198-017-4153-6)

5 Moseley KF. Type 2 diabetes and bone fractures. Current Opinion in Endocrinology, Diabetes and Obesity 201219 128-135. (https://doi. org/10.1097/MED.0b013e328350a6e1)

6 Yamamoto M, Yamaguchi T, Yamauchi M \& Sugimoto T. Low serum level of the endogenous secretory receptor for advanced glycation end products (esRAGE) is a risk factor for prevalent vertebral fractures independent of bone mineral density in patients with type 2 diabetes. Diabetes Care 200932 2263-2268. (https://doi.org/10.2337/ dc09-0901)

7 Petit MA, Paudel ML, Taylor BC, Hughes JM, Strotmeyer ES, Schwartz AV, Cauley JA, Zmuda JM, Hoffman AR, Ensrud KE et al. Bone mass and strength in older men with type 2 diabetes: the Osteoporotic Fractures in Men Study. Journal of Bone and Mineral Research 201025 285-291. (https://doi.org/10.1359/jbmr.090725)

8 Schwartz AV. Epidemiology of fractures in type 2 diabetes. Bone 2016 82 2-8. (https://doi.org/10.1016/j.bone.2015.05.032)

9 Starup-Linde J, Frost M, Vestergaard P \& Abrahamsen B. Epidemiology of fractures in diabetes. Calcified Tissue International 2017100 109-121. (https://doi.org/10.1007/s00223-016-0175-x)
10 Read SH, Kerssens JJ, McAllister DA, Colhoun HM, Fischbacher CM, Lindsay RS, McCrimmon RJ, McKnight JA, Petrie JR, Sattar N et al. Trends in type 2 diabetes incidence and mortality in Scotland between 2004 and 2013. Diabetologia 201659 2106-2113. (https:// doi.org/10.1007/s00125-016-4054-9)

11 Holden SE, Jenkins-Jones S, Morgan CL, Peters JR, Schernthaner G \& Currie CJ. Prevalence, glucose control and relative survival of people with type 2 diabetes in the UK from 1991 to 2013. Diabetic Medicine 201734 770-780. (https://doi.org/10.1111/dme.13332)

12 Mattishent K \& Loke YK. Meta-analysis: association between hypoglycaemia and serious adverse events in older patients. Journal of Diabetes and its Complications 201630 811-818. (https://doi. org/10.1016/j.jdiacomp.2016.03.018)

13 Rajpathak SN, Fu C, Brodovicz KG, Engel SS \& Lapane K. Sulfonylurea use and risk of hip fractures among elderly men and women with type 2 diabetes. Drugs and Aging 201532 321-327. (https://doi.org/10.1007/s40266-015-0254-0)

14 Johnston SS, Conner C, Aagren M, Ruiz K \& Bouchard J. Association between hypoglycaemic events and fall-related fractures in medicare-covered patients with type 2 diabetes. Diabetes, Obesity and Metabolism 201214 634-643. (https://doi.org/10.1111/j.14631326.2012.01583.x)

15 Kachroo S, Kawabata H, Colilla S, Shi L, Zhao Y, Mukherjee J, Iloeje U \& Fonseca V. Association between hypoglycemia and fall-related events in type 2 diabetes mellitus: analysis of a U.S. commercial database. Journal of Managed Care and Specialty Pharmacy 201521 243-253. (https://doi.org/10.18553/ jmcp.2015.21.3.243)

16 Vestergaard P, Rejnmark L \& Mosekilde L. Relative fracture risk in patients with diabetes mellitus, and the impact of insulin and oral antidiabetic medication on relative fracture risk. Diabetologia 200548 1292-1299. (https://doi.org/10.1007/s00125-005-1786-3)

17 Booth N. What are the read codes? Health Libraries Review 199411 177-182. (https://doi.org/10.1046/j.1365-2532.1994.1130177.x)

18 Carbonari DM, Saine ME, Newcomb CW, Blak B, Roy JA, Haynes K, Wood J, Gallagher AM, Bhullar H, Cardillo S et al. Use of demographic and pharmacy data to identify patients included within both the Clinical Practice Research Datalink (CPRD) and The Health Improvement Network (THIN). Pharmacoepidemiology and Drug Safety 201524 999-1003. (https://doi.org/10.1002/pds.3844)

19 Blak BT, Thompson M, Dattani H \& Bourke A. Generalisability of The Health Improvement Network (THIN) database: demographics, chronic disease prevalence and mortality rates. Informatics in Primary Care 201119 251-255.

20 Blak BT, Smith HT, Hards M, Maguire A \& Gimeno V. A retrospective database study of insulin initiation in patients with type 2 diabetes in UK primary care. Diabetic Medicine 201229 e191-e198. (https:// doi.org/10.1111/j.1464-5491.2012.03694.x)

21 Maguire A, Blak BT \& Thompson M. The importance of defining periods of complete mortality reporting for research using automated data from primary care. Pharmacoepidemiology and Drug Safety 2009 18 76-83. (https://doi.org/10.1002/pds.1688)

22 Dafoulas GE, Toulis KA, McCorry D, Kumarendran B, Thomas GN, Willis BH, Gokhale K, Gkoutos G, Narendran P \& Nirantharakumar K. Type 1 diabetes mellitus and risk of incident epilepsy: a population-based, open-cohort study. Diabetologia 2017 60 258-261. (https://doi.org/10.1007/s00125-016-4142-x)

23 Toulis KA, Hanif W, Saravanan P, Willis BH, Marshall T, Kumarendran B, Gokhale K, Ghosh S, Cheng KK, Narendran P et al. All-cause mortality in patients with diabetes under glucagon-like peptide-1 agonists: a population-based, open cohort study. Diabetes and Metabolism 201743 211-216. (https://doi.org/10.1016/j. diabet.2017.02.003)

24 Toulis KA, Willis BH, Marshall T, Kumarendran B, Gokhale K, Ghosh S, Thomas GN, Cheng KK, Narendran P, Hanif W et al. All-cause 
mortality in patients with diabetes under treatment with dapagliflozin: a population-based, open-cohort study in the health improvement network database. Journal of Clinical Endocrinology and Metabolism 2017 102 1719-1725. (https://doi.org/10.1210/jc.2016-3446)

25 Losada-Grande E, Hawley S, Soldevila B, Martinez-Laguna D, Nogues X, Diez-Perez A, Puig-Domingo M, Mauricio D \& PrietoAlhambra D. Insulin use and excess fracture risk in patients with type 2 diabetes: a propensity-matched cohort analysis. Scientific Reports 20177 3781. (https://doi.org/10.1038/s41598-017-03748-z)

26 Monami M, Cresci B, Colombini A, Pala L, Balzi D, Gori F, Chiasserini V, Marchionni N, Rotella CM \& Mannucci E. Bone fractures and hypoglycemic treatment in type 2 diabetic patients: a case-control study. Diabetes Care 200831 199-203. (https://doi. org/10.2337/dc07-1736)
27 Jia P, Bao L, Chen H, Yuan J, Liu W, Feng F, Li J \& Tang H. Risk of low-energy fracture in type 2 diabetes patients: a meta-analysis of observational studies. Osteoporosis International 201728 3113-3121. (https://doi.org/10.1007/s00198-017-4183-0)

28 Hung YC, Lin CC, Chen HJ, Chang MP, Huang KC, Chen YH $\&$ Chen CC. Severe hypoglycemia and hip fracture in patients with type 2 diabetes: a nationwide population-based cohort study. Osteoporosis International 201728 2053-2060. (https://doi. org/10.1007/s00198-017-4021-4)

29 Schwartz AV, Margolis KL, Sellmeyer DE, Vittinghoff E, Ambrosius WT, Bonds DE, Josse RG, Schnall AM, Simmons DL, Hue TF et al. Intensive glycemic control is not associated with fractures or falls in the ACCORD randomized trial. Diabetes Care 201235 1525-1531. (https://doi.org/10.2337/dc11-2184)

Received 13 June 2018

Revised version received 25 October 2018

Accepted 29 October 2018 